\title{
Continuing drug shortages affect North American patients
}

Published at www.cmaj.ca on Nov. 1

$\mathrm{P}$ harmacists across Canada say drug shortages are affecting patients and will likely continue to do so, despite assurances from manufacturers that they are trying to increase supplies.

"There is a problem, and it is significant," says Jeff Morrison, director of government relations for the Canadian Pharmacists Association.

The association surveyed members in October about whether they were unable to fill any prescriptions during their most recent shifts, and over the previous week. Of the more than 600 pharmacists who responded online, $84 \%$ had problems locating a drug during their most recent shift, and 94\% could not find at least one drug in the previous week.

The top four medications reported to be in short supply were amitriptyline, a tricyclic antidepressant; the antibiotics cephalexin and tetracycline; and metoclopramide, which is often used to alleviate nausea for patients taking chemotherapy.

The majority $(89 \%)$ of pharmacists also said that drug shortages have greatly increased over the past 12 months, while $70 \%$ said the shortages were affecting their patients' health.

"We're not professing that this is a scientific survey, but it's an interesting indicator and demonstrates that yes, drug shortages are a pretty big problem out there currently," Morrison says.

"They are saying that medication changes are confusing and disruptive for patients and may result in errors of use or non-compliance," he adds.

Dr. Robert Algie, president of the Ontario College of Family Physicians, says difficulties in getting penicillin, amoxicillin/clavulinic acid, cephalexin and tetracycline for his practice in Fort Frances, Ontario, have made it difficult to follow guidelines to avoid using newer antibiotics. "The shortages made us unable to practise evidence-based

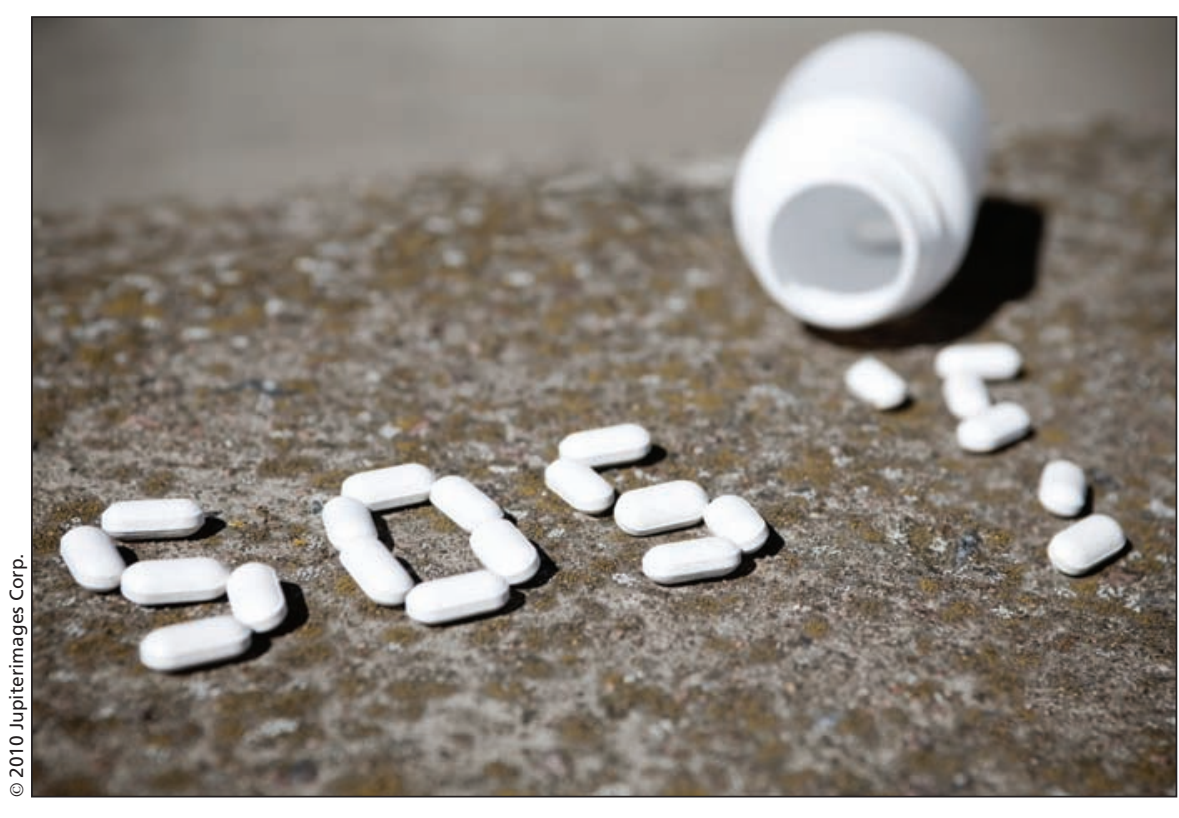

Although pharmacists say drug shortages are becoming a significant problem, the cause of those shortages appears a mystery to all parties.

medicine and forced us to use the newer broader-spectrum antibiotics," he says.

Algie calls the situation "frustrating," particularly when different formulations of drugs are unavailable and require substitutions. "It's a problem because you're having to go back and forth with the pharmacist - in Ontario, they can't automatically substitute a different formulation."

The United States Food and Drug Administration (FDA), meanwhile, lists more than 40 drugs in short supply. Valerie Jensen, associate director of the FDA's Center for Drug Evaluation and Research, says most of those are sterile injectable products, which are "on the brink" of being unavailable, she says.

Generic versions of injectable drugs and older brand-name versions are particularly hard to obtain, Jensen adds. "Fewer and fewer firms are making these. It's a complex manufacturing process compared to oral drugs and other drugs. These are not products that are really profitable."
When a limited number of companies make a drug and one has a manufacturing problem, a shortage results, Jensen says.

The Canadian Pharmacists Association did not ask its members to distinguish between generic and brand-name drugs when reporting shortages. But Dawn Martin, executive director of the Pharmacists Association of Saskatchewan, says the breadth of drugs that are in short supply within the wheat province range from folic acid to digoxin.

As for the cause of the shortages, she says, "it's hard to get a hold of it's like smoke."

The Canadian Pharmacists Association collected the supply data in advance of meetings with Health Canada, the Canadian Generic Pharmaceutical Association and Canada's Research-Based Pharmaceutical Companies (Rx\&D) to discuss the causes of the shortages.

"To our knowledge, the shortage affects mostly generic products and in many cases, the brand name product is still available even though a generic 
version is on the market," Russell Williams, president of Rx\&D, told $C M A J$ in a statement. "Where shortages are identified and the product is available, our members are doing their best to respond to the increased demand caused by the shortage of generic products to ensure patients have access to the medicines they need."

The Canadian Generic Pharmaceutical Association, meanwhile, indicated that the shortages are not a political response to drug program reforms in Ontario and other provinces.

The cause of the shortages is not clear but "generic pharmaceutical manufacturers are taking steps to address the shortages and expect the situation will improve significantly over the coming weeks and months," Jeff Keon, the association's president, said in an Aug. 17 statement.

Jeff Connell, the association's director of public affairs, initially said in response to CMAJ inquiries that the situation in Canada is improving but later qualified that to say the situation would improve.

Keon and Connell listed worldwide shortages of active pharmaceutical ingredients required to produce generic products, changes to regulatory standards and requirements, production issues, and changes in production equipment or processes as possible reasons for shortages, but stressed the cause is not yet clear.

"I have not been able to identify one single particular reason for the shortages in supply of prescription drugs in Canada, the United States or Europe," Connell states in an email.

The FDA, though, has not seen a recent increase in oral product shortages, or an increase in shortages of raw materials such as active ingredients, although these have been issues in the past, Jensen says. As for changes in regulatory standards and requirements, "we're not aware of any," she adds.

American patients have been affected by some shortages, including a critical lack this summer of propofol, an injectable anesthetic, Jensen says. That particular shortage occurred when two of the three firms that make propofol in the US had quality issues, including one with a risk of microbial contamination.

"Supplies were really not meeting demand and surgeries may have had to be cancelled or postponed - we have a public email account and we were getting those reports," Jensen says. The situation was so dire that FDA had to temporarily import the product from a European supplier.

But finding overseas suppliers is not always possible and no one can force domestic firms to ramp up productions, she adds. "We encourage firms to have extra capacity on hand and to increase inventories and have a little bit of a buffer just in case, but those aren't things that the FDA can require." Laura Eggertson, Ottawa, Ont.

DOI:10.1503/cmaj.109-3712 